\title{
EXTENSIONS OF LINMAP MODEL FOR MULTI CRITERIA DECISION MAKING WITH GREY NUMBERS
}

\author{
Seyed Hossein Razavi Hajiagha ${ }^{1}$, Shide Sadat Hashemi ${ }^{2}$ \\ Edmundas Kazimieras Zavadskas ${ }^{3}$, Hadi Akrami ${ }^{4}$
}

\author{
${ }^{1,4}$ Institute for Trade Studies and Research, Tehran, Iran \\ ${ }^{2}$ Faculty of management and accounting, Allame Tabatabaei University, Tehran, Iran \\ ${ }^{3}$ Vilnius Gediminas Technical University, Institute of Internet and Intelligent Technologies, \\ Sauletekio al. 11, LT-10223 Vilnius, Lithuania \\ E-mail: ${ }^{1}$ sh.razavi@st.atu.ac.ir; ${ }^{2}$ shide_hashemi@yahoo.com; \\ 3edmundas.zavadskas@vgtu.lt (correspondingauthor); ${ }^{3}$ hadi.akrami@gmail.com
}

Received 03 January 2012; accepted 06 August 2012

\begin{abstract}
The linear programming technique for multidimensional analysis of preference, known as LINMAP is one of the existing well-known ideal seeking methods for multi attribute decision making problems. This method originally is proposed under crisp and deterministic circumstances. However, uncertainty is an indubitable property of decision making problems. In this paper, a new version of LINMAP-G is proposed where the decision maker's judgments are expressed as grey numbers. Like original LINMAP method, the grey ideal solution and attributes weight vector is determined and alternatives are ranked according to their weighted distance from determined ideal point. Application of the proposed method is illustrated in two numerical examples.
\end{abstract}

Keywords: MCDM, LINMAP-G, Uncertain Decision making, Grey data, Positive ideal solution, Grey Euclidean Distance.

Reference to this paper should be made as follows: Razavi Hajiagha, S. H; Hashemi, S. S.; Zavadskas, E. K.; Akrami, H. 2012. Extensions of LINMAP model for multi criteria decision making with grey numbers, Technological and Economic Development of Economy 18(4): 636-650.

JEL Classification: C02, C44, D81. 


\section{Introduction}

Decision makers always seek a criterion to appraise their decisions. In this context, decisionmaking methods arise when decision maker simultaneously envisages various criteria for evaluating his or her decisions favorite (Kuo et al. 2008). Such a problem is the subject of multiple criteria decision making (MCDM) methods (Zavadskas, Turskis 2011; Peng et al. 2011; Kou et al. 2012). This class is further divided into multi objective decision making (MODM) and multi attribute decision making (MADM) (Climaco 1997). A formalized definition of MADM problems can be stated as follows.

Let we have a nonempty and finite set of decision alternatives, i.e. $A_{1}, A_{2}, \ldots, A_{m}$, and there are a finite set of goals, attributes or criteria, i.e. $C_{1}, C_{2}, \ldots, C_{n}$, according to which the desirability of an alternative is to be judged. The aim of MADM is to determine the optimal alternative with the highest degree of desirability with respect to all relevant goals (Zimmerman 1987). An optimal alternative in MADM problems can be defined as an alternative $A^{\star}$ that has the highest value in all decision-making criteria. Usually, MADM problems do not have an optimal solution in practice and current methods seek an alternative with the highest degree of satisfaction for decision makers. In last decades, MADM techniques have a wide application in different areas that concern with selection.

Multi attribute decision making methods require decision makers judgments and evaluations about alternatives performance regard to multiple attributes. These judgments are a subject of uncertainty. Indeed, decision makers do not have complete information about alternatives or their conditions regard to a certain attribute. Therefore, it will be so difficult for them to express their evaluations based on exact numbers. Hence, uncertainty contexts are widely applied in MADM problems.

Fuzzy set theory (FST) was developed by Zadeh (Zadeh 1965) as a generalized form of the classical set theory that assigns a membership degree to each element of a given set in a universe. FST is one of the well-known paradigms in studying systems with uncertainty. Bellman and Zadeh (Bellman, Zadeh 1970) have introduced the concept of decision making under fuzzy environment. Afterward, MADM techniques have been extended under fuzzy environment (Aouam et al. 2003; Yazdani et al. 2011; Xu 2004; Li, Yang 2004; Wang, Chuu 2004; Hu et al. 2004; Antucheviciene et al. 2011; Kersuliene, Turskis 2011; Brauers et al. 2011; Fouladgar et al. 2011; Balezentis, Balezentis 2011).

Another paradigm of uncertainty is developed such that the crisp numbers are substituted with grey numbers (Deng 1982). Interval numbers also have a wide application in decision making field with TOPSIS (Chen, Tzeng 2004; Jahanshahloo et al. 2006; Lin et al. 2008; Zavadskas et al. 2010a; Tsaur 2011; Yue 2011), with PROMETHEE (Le Teno, Mareschal 1998), with ELECTRE (Vahdani et al. 2010; Özcan et al. 2011), with COPRAS-G (Zavadskas et al. 2010b; Hashemkhani Zolfani et al. 2011), with ARAS-G (Turskis, Zavadskas 2010; Zavadskas et al. 2010c), with SAW-G (Zavadskas et al. 2010a), with MOORA (Stanujkic et al. 2012). An interval number can be considered as a number whose exact value is unknown, but a range within which the value lies is known (Moore 1966).

The Linear Programming Technique for Multidimensional Analysis of Preference (LINMAP) was developed by Srinivasan and Schocker (Srinivasan, Shocker 1973) as one of the MADM tech- 
niques that determines the preference order among a set of alternatives by determination of weight vector $w$ and positive ideal solution (PIS) vector. However, the LINMAP can only deal with MADM problems in crisp environments. Xia et al. (Xia et al. 2006) developed LINMAP method for MADM problems under fuzzy environment. Li and Sun (Li, Sun 2007) developed LINMAP method for MADM problems with linguistic variables and incomplete preference information. $\mathrm{Li}$ (2008) also developed this method under intuitionistic fuzzy environment. Considering the simplicity and clearness of grey numbers in expressing the uncertainty and lack of knowledge, in this paper, a LINMAP method is extended with grey data. The rest of the paper is organized as follows: Section 2 briefly introduces the grey numbers and their operations. MADM problems with grey data are expressed in section 3 . The extended grey LINMAP model and proposed decision process is introduced in section 4 . The proposed method is illustrated with an example in section 5. Finally, the paper is concluded in section 6 .

\section{Grey numbers}

As stated in previous section, a grey number can be indicated as a range. In fact, a number $x$ is called an grey number when its exact value is unknown and only it is known that $x \in[\underline{x}, \bar{x}]$, where $\underline{x}$ is the lower bound and $\bar{x}$ is the upper bound, such that $x \prec \bar{x}$. Arithmetic operations on interval numbers are introduced by Moore (Moore 1966). If $x=[\underline{x}, \bar{x}]$ and $y=[\underline{y}, \bar{y}]$ are two grey numbers, then:

$$
\begin{gathered}
x+y=[\underline{x}+\underline{y}, \bar{x}+\bar{y}], \\
x-y=[\underline{x}-\bar{y}, \bar{x}-\underline{y}], \\
x \times y=[\min (\underline{x} \underline{y}, \underline{x} \bar{y}, \bar{x} \underline{y}, \overline{x y}), \max (\underline{x} \underline{y}, \underline{x} \bar{y}, \bar{x} \underline{y}, \overline{x y})], \\
x \div y=[\underline{x}, \bar{x}] \times\left[\frac{1}{\bar{y}}, \frac{1}{y}\right] .
\end{gathered}
$$

The center, $x_{C}$, and width, $x_{W}$ of a grey number $x$ are defined as follows (Ishibuchi, Tanaka 1990):

$$
\begin{aligned}
& x_{C}=\frac{1}{2}(\underline{x}+\bar{x}), \\
& x_{W}=\frac{1}{2}(\bar{x}-\underline{x}) .
\end{aligned}
$$

\section{Grey MADM problem definition}

Consider an MADM problem that consist evaluation of a set of $m$ alternatives regard to a set of $n$ attributes. In classic form, ratings of alternatives regard to attributes are stated with crisp data. However in many situations, and due to uncertainty or lack of knowledge, the crispness of ratings is an unfair assumption. Therefore, suppose that the ratings values are expressed 
in form of grey numbers. If $A_{1}, A_{2}, \ldots, A_{m}$ are $m$ possible alternatives and $C_{1}, C_{2}, \ldots, C_{n}$ criteria over which alternatives performance are measured, and $x_{i j} \in\left[\underline{x}_{i j}, \bar{x}_{i j}\right]$ is the rating of alternative $A_{i}$, with respect to criterion $C_{j}$, then a grey MADM problem can be concisely defined in a decision matrix as follows.

\begin{tabular}{c|c|c|c|c} 
& $C_{1}$ & $C_{2}$ & $\cdots$ & $C_{n}$ \\
\hline$A_{1}$ & {$\left[\underline{x}_{11}, \bar{x}_{11}\right]$} & {$\left[\underline{x}_{12}, \bar{x}_{12}\right]$} & $\ldots$ & {$\left[\underline{x}_{1 n}, \bar{x}_{1 n}\right]$} \\
$A_{2}$ & {$\left[\underline{x}_{21}, \bar{x}_{21}\right]$} & {$\left[\underline{x}_{22}, \bar{x}_{22}\right]$} & $\ldots$ & {$\left[\underline{x}_{2 n}, \bar{x}_{2 n}\right]$} \\
$\vdots$ & $\vdots$ & $\vdots$ & $\ddots$ & $\vdots$ \\
$A_{m}$ & {$\left[\underline{x}_{m 1}, \bar{x}_{m 1}\right]$} & {$\left[\underline{x}_{m 2}, \bar{x}_{m 2}\right]$} & $\ldots$ & {$\left[\underline{x}_{m n}, \bar{x}_{m n}\right]$} \\
\hline
\end{tabular}

In addition, the weigh vector of criteria is defined as $W=\left(w_{1}, w_{2}, \ldots, w_{n}\right)$ that $w_{j}$ is the importance weight of criterion $j$. The problem here is to rank the alternative set's elements.

\section{Grey LINMAP}

In this section, the proposed method of LINMAP-G (Srinivasan, Shocker 1973; Hwang, Yoon 1981) with grey data is developed. It is noted that the LINMAP-G method seeks a positive ideal solution (PIS) and a weight vector $w$ that minimizes the distance of a set of preference relations among alternatives that are expressed priori by decision makers from unknown PIS.

\subsection{Normalization of Grey decision matrix}

An intrinsic aspect of MADM problems is that different attributes have different dimensions that make their comparison impossible. Therefore, an initial step before the decision making process, is to normalize the grey decision matrix, defined in previous section. Different procedures are introduced to normalize grey decision matrix. In this paper the method proposed in Jahanshahloo et al. (Jahanshahloo et al. 2006) is applied by modifications. If attribute $j$ is as profit (maximization) type, its normalized values are calculated as:

$$
n_{i j}=\left[\frac{\underline{x}_{i j}}{\sqrt{\sum_{i=1}^{m} \underline{x}_{i j}^{2}+\bar{x}_{i j}^{2}}}, \frac{\bar{x}_{i j}}{\sqrt{\sum_{i=1}^{m} \underline{x}_{i j}^{2}+\bar{x}_{i j}^{2}}}\right] .
$$

Otherwise, if attribute $\mathrm{j}$ is as cost (minimization) type, its normalized values are calculated as:

$$
n_{i j}=\left[1-\frac{\bar{x}_{i j}}{\sqrt{\sum_{i=1}^{m} \underline{x}_{i j}^{2}+\bar{x}_{i j}^{2}}}, 1-\frac{\underline{x}_{i j}}{\sqrt{\sum_{i=1}^{m} \underline{x}_{i j}^{2}+\bar{x}_{i j}^{2}}}\right] .
$$




\subsection{Grey LINMAP modeling process}

The main idea of LINMAP-G method is to determine an unknown PIS vector, like $P I S=A^{*}=\left(x_{1}^{*}, x_{2}^{*}, \ldots, x_{n}^{*}\right)$, where $x_{i}^{*}=\left[\underline{x}_{i}^{*}, \bar{x}_{i}^{*}\right]$. Then, the best alternative is chosen as the nearest one to this PIS vector. A note here is to define the distance between two grey vectors.

If $A_{i}=\left(x_{i 1}, x_{i 2}, \ldots, x_{i n}\right)$ and $A^{*}=\left(x_{1}^{*}, x_{2}^{*}, \ldots, x_{n}^{*}\right)$ are two grey vectors, and $W=\left(w_{1}, w_{2}, \ldots, w_{n}\right)$ is a weight vector, the weighted grey numbers Euclidean distance is defined as follows:

$$
d_{i}=\sqrt{\sum_{j=1}^{n} w_{j}\left[\left(\underline{x}_{i j}-\underline{x}_{j}^{*}\right)^{2}+\left(\bar{x}_{i j}-\bar{x}_{j}^{*}\right)^{2}\right]} .
$$

Now, the variable $s_{i}=d_{i}^{2}$ is defined. Suppose that decision maker specified an order relations set between alternatives as $\Omega$, where each $(k, l) \in \Omega$ means that decision maker preferred alternative $A_{k}$ to alternative $A_{l}$.

For a given PIS and weight vector $w$, alternative $A_{k}$ is closer to PIS than alternative $A_{l}$, if $s_{k} \leq s_{l}$. In this case, the ranking obtained by ( $w$, PIS) is consistent with decision maker's preference. Otherwise, if $s_{k} \succ s_{l}$ then the ranking obtained by ( $w$, PIS) is inconsistent with decision maker's preference.

The inconsistency between alternatives $A_{k}$ and $A_{l}$ ranking based on $s_{k}$ and $s_{l}$ with preference relations that are determined by decision maker is measured by an inconsistency index $\left(s_{l}-s_{k}\right)^{-}$:

$$
\left(s_{l}-s_{k}\right)^{-}=\left\{\begin{array}{ll}
s_{k}-s_{l} & \text { if } s_{k} \succ s_{l} \\
0 & \text { if } s_{k} \leq s_{l}
\end{array} .\right.
$$

In fact, the alternatives $A_{k}$ and $A_{l}$ ranking is consistent with decision maker's preferences if $s_{k} \leq s_{l}$ and $\left(s_{l}-s_{k}\right)^{-}$will be equal to zero. Otherwise, if $s_{k} \succ s_{l}$ the rankings are not consistent and their inconsistency will be equal to $\left(s_{l}-s_{k}\right)^{-}=s_{k}-s_{l}$. Therefore:

$$
\left(s_{l}-s_{k}\right)^{-}=\max \left(0, s_{k}-s_{l}\right) \text {. }
$$

Now, the total inconsistency index is defined as follows:

$$
I=\sum_{(k, j) \in \Omega}\left(s_{k}-s_{l}\right)^{-}=\sum_{(k, j) \in \Omega} \max \left(0, s_{k}-s_{l}\right) .
$$

Similarly, the consistency index is defined as follows:

$$
\left(s_{l}-s_{k}\right)^{+}=\left\{\begin{array}{ll}
s_{l}-s_{k} & \text { if } s_{k} \leq s_{l} \\
0 & \text { if } s_{k} \succ s_{l}
\end{array} .\right.
$$

Eq. (13) can be written as follows:

$$
\left(s_{l}-s_{k}\right)^{+}=\max \left(0, s_{l}-s_{k}\right) .
$$

Therefore, total consistency index is defined as follows:

$$
C=\sum_{(k, l) \in \Omega}\left(s_{l}-s_{k}\right)^{+}=\sum_{(k, l) \in \Omega} \max \left(0, s_{l}-s_{k}\right) .
$$


Note that whether $s_{k} \leq s_{l}$ or $s_{k} \succ s_{l}$, the following relation is hold:

$$
\left(s_{l}-s_{k}\right)^{+}-\left(s_{l}-s_{k}\right)^{-}=s_{l}-s_{k} .
$$

The grey LINMAP-G model to determine the PIS $A^{*}=\left(x_{1}^{*}, x_{2}^{*}, \ldots, x_{n}^{*}\right)$ and weight vector $W=\left(w_{1}, w_{2}, \ldots, w_{n}\right)$ can be constructed as follows:

$$
\begin{aligned}
& \operatorname{Max} C \\
& \text { S.T. } C-B \geq h \\
& w_{j} \geq \varepsilon \quad j=1,2, \ldots, n,
\end{aligned}
$$

where, $h$ is a constant that is determined by decision maker. Also, $\varepsilon \succ 0$ is a sufficiently small real value that guarantees that obtained weights are greater than zero. The objective of model (17) is to maximize the consistency index $C$, while it will be greater than $I$ at least as pre-determined value of $h$.

Using Eq. (15) and (16), the model (17) is translated to:

$$
\begin{aligned}
& \operatorname{Max} \sum_{(k, l) \in \Omega} \max \left(0, s_{l}-s_{k}\right) \\
& \text { S.T. } \sum_{(k, l) \in \Omega}\left(s_{l}-s_{k}\right) \geq h \\
& w_{j} \geq \varepsilon \quad j=1,2, \ldots, n .
\end{aligned}
$$

The variable $\lambda_{k l}$ is introduced as follows:

$$
\lambda_{k l}=\max \left(0, s_{l}-s_{k}\right) .
$$

For each pair $(k, l) \in \Omega$ the following relations are hold:

and

$$
\lambda_{k l} \geq 0
$$

$$
\lambda_{k l} \geq s_{l}-s_{k} .
$$

Substituting Eq. (19) - (21), the model (18) is transformed to the following model:

$$
\begin{array}{ll}
\operatorname{Max} \sum_{(k, l) \in \Omega} \lambda_{k l}, & \\
\text { S.T. } h+\sum_{(k, l) \in \Omega}\left(s_{k}-s_{l}\right) \leq 0, & \\
s_{k}-s_{l}+\lambda_{k l} \geq 0 & \forall(k, l) \in \Omega, \\
\lambda_{k l} \geq 0 \quad & \forall(k, l) \in \Omega, \\
w_{j} \geq \varepsilon \quad j=1,2, \ldots, n .
\end{array}
$$

The final LINMAP-G model is achieved by acquisition of a corresponding relation for $s_{k}-s_{l}$. Using Eq. (9) and the definition of variable $s_{i}$, this relation is obtained as follows:

$$
s_{k}-s_{l}=\sum_{j=1}^{n} w_{j}\left[\left(\underline{x}_{k j}-\underline{x}_{j}^{*}\right)^{2}+\left(\bar{x}_{k j}-\bar{x}_{j}^{*}\right)^{2}\right]-\sum_{j=1}^{n} w_{j}\left[\left(\underline{x}_{l j}-\underline{x}_{j}^{*}\right)^{2}+\left(\bar{x}_{l j}-\bar{x}_{j}^{*}\right)^{2}\right] .
$$


The extended form of the above equation after calculation of squares and factorization is as follows:

$$
\begin{aligned}
& s_{k}-s_{l}=\sum_{j=1}^{n} w_{j}\left[\left(\underline{x}_{k j}^{2}+\bar{x}_{k j}^{2}-\underline{x}_{l j}^{2}-\bar{x}_{l j}^{2}\right)\right]+\sum_{j=1}^{n} 2 w_{j} \underline{x}_{j}^{*}\left(\underline{x}_{l j}-\underline{x}_{k j}\right) \\
& +\sum_{j=1}^{n} 2 w_{j} \bar{x}_{j}^{*}\left(\bar{x}_{l j}-\bar{x}_{k j}\right) .
\end{aligned}
$$

The model (22) is now transformed into the following model, which is called grey LINMAP-G model.

$$
\begin{aligned}
& \operatorname{Max} \sum_{(k, l) \in \Omega} \lambda_{k l}, \\
& \text { S.T. } h+\sum_{j=1}^{n} w_{j} \sum_{(k, l) \in \Omega}\left(\underline{x}_{k j}^{2}+\bar{x}_{k j}^{2}-\underline{x}_{l j}^{2}-\bar{x}_{l j}^{2}\right)+\sum_{j=1}^{n} \underline{v}_{j} \sum_{(k, l) \in \Omega}\left(\underline{x}_{l j}-\underline{x}_{k j}\right) \\
& +\sum_{j=1}^{n} 2 \bar{v}_{j} \sum_{(k, l) \in \Omega}\left(\bar{x}_{l j}-\bar{x}_{k j}\right) \leq 0, \\
& \sum_{j=1}^{n} w_{j}\left[\left(\underline{x}_{k j}^{2}+\bar{x}_{k j}^{2}-\underline{x}_{l j}^{2}-\bar{x}_{l j}^{2}\right)\right]+\sum_{j=1}^{n} 2 \underline{v}_{j}\left(\underline{x}_{l j}-\underline{x}_{k j}\right) \\
& +\sum_{j=1}^{n} 2 \bar{v}_{j}\left(\bar{x}_{l j}-\bar{x}_{k j}\right)+\lambda_{k l} \geq 0 \quad \forall(k, l) \in \Omega, \\
& \lambda_{k l} \geq 0 \quad \forall(k, l) \in \Omega, \\
& \underline{v}_{j} \leq \bar{v}_{j} \quad j=1,2, \ldots, n, \\
& w_{j} \geq \varepsilon \quad j=1,2, \ldots, n,
\end{aligned}
$$

where,

$$
\underline{v}_{j}=w_{j} \underline{x}_{j}^{*}
$$

and

$$
\bar{v}_{j}=w_{j} \bar{x}_{j}^{*}
$$

Note that constraints $\underline{v}_{j} \leq \bar{v}_{j} j=1,2, \ldots, n$ are added to guarantee the grey property of obtained PIS. By solving the model (24), the optimal values of $\underline{v}_{j}, \bar{v}_{j}$ and $w_{j}$ are determined. Then, the PIS solution $A^{*}=\left(x_{1}^{*}, x_{2}^{*}, \ldots, x_{n}^{*}\right)$ and weight vector $W=\left(w_{1}, w_{2}, \ldots, w_{n}\right)$ are determined. The optimal weights of attributes can be determined after normalization of weight vector $W$. Finally, the ranking of alternatives are specified by calculation of $s_{i}$ variables for all alternatives and ascending sort of these values.

Figure 1 shows an algorithm about the decision making process with LINMAP-G method. It is possible that decision maker has some viewpoints regard to weight vector, such that he/ she do not want none of the attribute's weights be greater than other's weights. This set of constraints can be added to model as $u_{k j} \leq w_{k} / w_{j} \leq l_{k j}, k, j=1,2, \ldots, n, k \neq j$. 


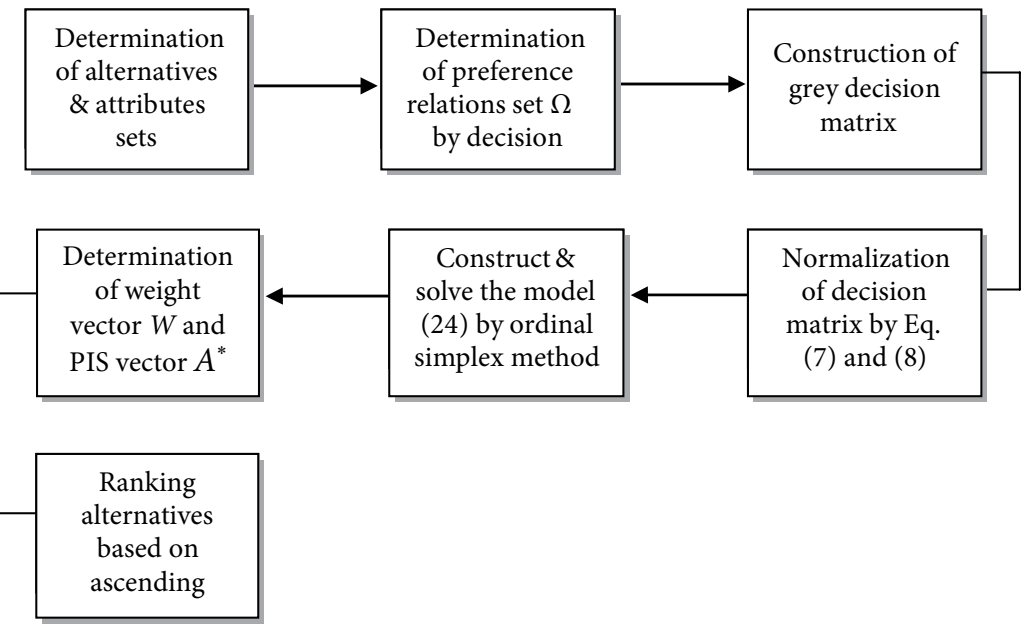

Fig. 1. Decision making process by LIMAP-G model

\section{Numerical example}

In this section, two numerical examples are solved by proposed LINMAP-G decision making process.

\subsection{Ranking of constructing projects}

The first study is done on a relatively small instance. This example is about a company that wants to rank its target market sectors. The company's market is divided into five different sectors A, B, C, D, and E that are evaluated based on four attributes: three attributes include (1) market size, (2) market growth and (3) consistency with company's mission as profit attributes and a (4) structural risk attribute as cost attributes. The grey decision matrix is constructed as follows (see Table 1).

Table 1. Grey decision matrix (example 1)

\begin{tabular}{ccccc}
\hline & 1 & 2 & 3 & 4 \\
\hline A & {$[6,7]$} & {$[3,4]$} & {$[4,5]$} & {$[6,7]$} \\
\cline { 2 - 5 } B & {$[4,5]$} & {$[5,6]$} & {$[5,6]$} & {$[6,7]$} \\
\cline { 2 - 5 } C & {$[5,7]$} & {$[6,7.5]$} & {$[4,5]$} & {$[3,4]$} \\
n D & {$[7,8]$} & {$[4,5]$} & {$[6,8]$} & {$[5,6]$} \\
E & {$[6,8]$} & {$[5,6]$} & {$[7,9]$} & {$[7,8]$} \\
\hline
\end{tabular}

Assume that decision makers have specified their preferences between alternatives as $\Omega=\{(2,1),(3,2),(4,3),(5,4)\}$. The first step is to normalize the decision matrix. Attributes 1-3 are normalized based on Eq. (7) and the attribute 4 by Eq. (8). The normalized decision matrix is shown in Table 2. 
644 S. H. Razavi Hajiagha et al. Extensions of LINMAP model for multi criteria decision making ...

Table 2. Normalized grey decision matrix (example 1)

\begin{tabular}{ccccc}
\hline & 1 & 2 & 3 & 4 \\
\hline A & {$[0.295,0.344]$} & {$[0.179,0.239]$} & {$[0.207,0.259]$} & {$[0.649,0.699]$} \\
\cline { 2 - 5 } B & {$[0.197,0.246]$} & {$[0.299,0.358]$} & {$[0.259,0.311]$} & {$[0.598,0.649]$} \\
\cline { 2 - 5 } C & {$[0.246,0.344]$} & {$[0.358,0.448]$} & {$[0.207,0.259]$} & {$[0.799,0.849]$} \\
\cline { 2 - 5 } D & {$[0.344,0.394]$} & {$[0.299,0.311]$} & {$[0.311,0.414]$} & {$[0.699,0.749]$} \\
\cline { 2 - 5 } E & {$[0.295,0.394]$} & {$[0.358,0.362]$} & {$[0.362,0.466]$} & {$[0.598,649]$} \\
\hline
\end{tabular}

In the next step, the grey LINMAP-G method is developed according to Eq. (24) as follows. Assume that decision maker wants that none of the attributes weights be more than three times greater than the others. Note that $h=1$ and $\varepsilon=0.001$.

$$
\begin{aligned}
& \operatorname{Max} \lambda_{21}+\lambda_{32}+\lambda_{34}+\lambda_{54} \\
& 1+0.0363 w_{1}+0.1285 w_{2}+0.2386 w_{3}-0.1302 w_{4} \\
& +2\left(-0.1195 \underline{v}_{2}-0.1553 \underline{v}_{3}\right) \\
& +2\left(-0.0492 \bar{v}_{1}-0.1195 \bar{v}_{2}-0.2071 \bar{v}_{3}+0.0502 \bar{v}_{4}\right) \leq 0 \\
& -0.1065 w_{1}+0.1285 w_{2}+0.0536 w_{3}-0.1302 w_{4} \\
& +2\left(0.098 \underline{v}_{1}-0.119 \underline{v}_{2}-0.052 \underline{v}_{3}+0.05 \underline{v}_{4}\right) \\
& +2\left(-0.098 \bar{v}_{1}-0.119 \bar{v}_{2}-0.052 \bar{v}_{3}+0.05 \bar{v}_{4}\right)+\lambda_{21} \leq 0 \\
& 0.0799 w_{1}+0.1115 w_{2}-0.0536 w_{3}+0.5814 w_{4} \\
& +2\left(-0.049 \underline{v}_{1}-0.06 \underline{v}_{2}+0.052 \underline{v}_{3}-0.201 \underline{v}_{4}\right) \\
& +2\left(-0.098 \bar{v}_{1}-0.09 \bar{v}_{2}+0.0521 \bar{v}_{3}-0.201 \bar{v}_{4}\right)+\lambda_{32} \leq 0 \\
& -0.0944 w_{1}+0.1829 w_{2}-0.1582 w_{3}+0.3108 w_{4} \\
& +2\left(0.098 \underline{v}_{1}-0.119 \underline{v}_{2}+0.104 \underline{v}_{3}-0.1 \underline{v}_{4}\right) \\
& +2\left(0.049 \bar{v}_{1}-0.149 \bar{v}_{2}+0.155 \bar{v}_{3}-0.1 \bar{v}_{4}\right)+\lambda_{34} \leq 0 \\
& 0.0315 w_{1}+0.0714 w_{2}+0.0804 w_{3}-0.2705 w_{4} \\
& +2\left(0.049 \underline{v}_{1}-0.6 \underline{v}_{2}-0.052 \underline{v}_{3}+0.1 \underline{v}_{4}\right) \\
& +2\left(-0.06 \bar{v}_{2}-0.052 \bar{v}_{3}+0.1 \bar{v}_{4}\right)+\lambda_{54} \leq 0 \\
& w_{k} / w_{j} \leq 3, k, j=1,2, \ldots, n, k \neq j \\
& \lambda_{21}, \lambda_{32}, \lambda_{34}, \lambda_{54} \geq 0 \\
& \underline{v}_{j} \leq \bar{v}_{j} j=1,2,3,4 \\
& w_{j} \geq 0.001 \quad j=1,2,3,4
\end{aligned}
$$

The optimal solution of the above model is as follows:

$$
\begin{aligned}
& W^{*}=\left(w_{1}, w_{2}, w_{3}, w_{4}\right)=(0.35,1.05,1.05,0.35), \\
& V^{*}=((0.299,0.299),(0,0),(0,3.54),(0.713,0.713)) .
\end{aligned}
$$


Now, the PIS $A^{*}$ can be derived as $A^{*}=V^{*} / W^{*}$

$$
A^{*}=((0.854,0.854),(0,0),(0,3.37),(2.037,2.037)) \text {. }
$$

Now, thesquaredistances $s_{i}$ fromPIS $A^{*}$ are $s_{1}=11.813, s_{2}=11.816, s_{3}=11.813, s_{4}=10.810$ and $s_{5}=10.813$. Therefore, the ranking order of alternatives are $\mathrm{D} \succ \mathrm{E} \succ \mathrm{A}=\mathrm{C} \succ \mathrm{B}$.

\subsection{Contractor ranking}

This example is solved in (Jahanshahloo et al. 2006) through grey TOPSIS method. The problem is to rank 15 bank branches based on four financial attributes. Grey decision matrix is shown in Table 3. Assume that the decision maker determines his/her preferences between branches as follows:

$$
\Omega=\left\{\begin{array}{l}
(1,2),(3,2)(1,3)(3,4),(4,5),(6,4),(6,7),(8,7), \\
(9,8),(9,10),(10,11),(12,11),(13,12),(13,14),(15,14)
\end{array}\right\} .
$$

Table 3. Grey decision matrix (example 2)

\begin{tabular}{ccccc}
\hline & $C_{1}$ & $C_{2}$ & $C_{3}$ & $C_{4}$ \\
\hline$A_{1}$ & {$[500.37,961.37]$} & {$[2696995,3126798]$} & {$[26364,38254]$} & {$[965.97,6957.33]$} \\
\cline { 2 - 5 }$A_{2}$ & {$[873.7,1775.5]$} & {$[1027546,1061260]$} & {$[3791,50308]$} & {$[2285.03,3174]$} \\
\cline { 2 - 5 }$A_{3}$ & {$[95.93,196.39]$} & {$[1145235,1213541]$} & {$[22964,26846]$} & {$[207.98,510.93]$} \\
\cline { 2 - 5 }$A_{4}$ & {$[848.07,1752.66]$} & {$[390902,395241]$} & {$[492,1213]$} & {$[63.32,92.3]$} \\
$A_{5}$ & {$[58.69,120.47]$} & {$[144906,165818]$} & {$[18053,18061]$} & {$[176.58,370.81]$} \\
$A_{6}$ & {$[464.39,955.61]$} & {$[408163,416416]$} & {$[40539,48643]$} & {$[4654.71,5882.53]$} \\
$A_{7}$ & {$[155.29,342.89]$} & {$[335070,410427]$} & {$[33797,44933]$} & {$[560.26,2506.67]$} \\
$A_{8}$ & {$[1752.31,3629.54]$} & {$[700842,768593]$} & {$[1437,1519]$} & {$[58.89,86.86]$} \\
$A_{9}$ & {$[244.34,495.78]$} & {$[641680,696338]$} & {$[11418,24108]$} & {$[1070.81,2283.08]$} \\
\cline { 2 - 5 }$A_{10}$ & {$[730.27,1417.11]$} & {$[453170,481943]$} & {$[2719,2955]$} & {$[375.07,559.85]$} \\
$A_{11}$ & {$[454.75,931.24]$} & {$[309670,642598]$} & {$[2016,2617]$} & {$[936.62,1468.45]$} \\
\cline { 2 - 5 }$A_{12}$ & {$[303.58,630.01]$} & {$[286149,317186]$} & {$[14918,27070]$} & {$[1203.79,4335.24]$} \\
$A_{13}$ & {$[658.81,1345.58]$} & {$[321435,347848]$} & {$[6616,8045]$} & {$[200.36,399.8]$} \\
$A_{14}$ & {$[420.18,860.79]$} & {$[618105,835839]$} & {$[24425,40457]$} & {$[2781.24,4555.42]$} \\
$A_{15}$ & {$[144.68,292.15]$} & {$[119948,120208]$} & {$[1494,1749]$} & {$[282.73,471.22]$} \\
\hline & & & & \\
\hline
\end{tabular}

The next step according to Figure 1 is to normalize the grey decision matrix. Table 4 shows the normalized decision matrix (while all attributes are as maximizing type, Eq. (7) is used here). Then, the grey model (24) is constructed and solved. In this model $h=1$ and $\varepsilon=0.01$ are considered. The obtained solution is as follows:

$$
W^{*}=(0.086,0.086,0.173,0.173), V^{*}=((0,0),(0.1332,0.385),(0,0.1),(0,0)) \text {. }
$$


646 S. H. Razavi Hajiagha et al. Extensions of LINMAP model for multi criteria decision making ...

Table 4. Normalized grey decision matrix (example 2)

\begin{tabular}{ccccc}
\hline & $C_{1}$ & $C_{2}$ & $C_{3}$ & $C_{4}$ \\
\hline$A_{1}$ & {$[0.0856,0.1645]$} & {$[0.5176,0.6001]$} & {$[0.1974,0.2865]$} & {$[0.0706,0.5086]$} \\
\cline { 2 - 5 }$A_{2}$ & {$[0.1495,0.3038]$} & {$[0.1972,0.2037]$} & {$[0.0283,0.3768]$} & {$[0.1670,0.2320]$} \\
\cline { 2 - 5 }$A_{3}$ & {$[0.0164,0.0336]$} & {$[0.2198,0.2329]$} & {$[0.1720,0.2010]$} & {$[0.0152,0.0373]$} \\
\cline { 2 - 5 }$A_{4}$ & {$[0.1451,0.2999]$} & {$[0.0750,0.0758]$} & {$[0.0036,0.0090]$} & {$[0.0046,0.0067]$} \\
\cline { 2 - 5 }$A_{5}$ & {$[0.0100,0.0206]$} & {$[0.0278,0.0318]$} & {$[0.1352,0.1352]$} & {$[0.0129,0.0271]$} \\
$A_{6}$ & {$[0.0794,0.1635]$} & {$[0.0783,0.0799]$} & {$[0.3036,0.3643]$} & {$[0.3403,0.4300]$} \\
$A_{7}$ & {$[0.0265,0.0586]$} & {$[0.0643,0.0787]$} & {$[0.2531,0.3365]$} & {$[0.0409,0.1832]$} \\
$A_{8}$ & {$[0.2999,0.6211]$} & {$[0.1345,0.1475]$} & {$[0.0107,0.0113]$} & {$[0.0043,0.0063]$} \\
\cline { 2 - 5 }$A_{9}$ & {$[0.0418,0.0848]$} & {$[0.1231,0.1336]$} & {$[0.0855,0.1805]$} & {$[0.0782,0.1669]$} \\
$A_{10}$ & {$[0.1249,0.2425]$} & {$[0.0869,0.0925]$} & {$[0.0203,0.0221]$} & {$[0.0274,0.0409]$} \\
$A_{11}$ & {$[0.0788,0.1593]$} & {$[0.0594,0.0657]$} & {$[0.0151,0.0196]$} & {$[0.0684,0.1073]$} \\
\cline { 2 - 5 }$A_{12}$ & {$[0.0519,0.1078]$} & {$[0.0549,0.0608]$} & {$[0.1117,0.2027]$} & {$[0.0880,0.3169]$} \\
\cline { 2 - 5 }$A_{13}$ & {$[0.1127,0.2302]$} & {$[0.0616,0.0667]$} & {$[0.0495,0.0602]$} & {$[0.0146,0.0292]$} \\
$A_{14}$ & {$[0.0719,0.1473]$} & {$[0.1186,0.1604]$} & {$[0.1829,0.3030]$} & {$[0.2033,0.3330]$} \\
\cline { 2 - 5 }$A_{15}$ & {$[0.0247,0.0500]$} & {$[0.0230,0.0230]$} & {$[0.0111,0.0131]$} & {$[0.0206,0.0344]$} \\
\hline
\end{tabular}

Now, the PIS $A^{*}$ can be derived as $A^{*}=((0,0),(1.54,4.47),(0.0 .578),(0,0))$. Table 5 shows the square distances and ranking of alternatives by proposed.

Table 5. Square distances and ranking of alternatives (example 2)

\begin{tabular}{lcc}
\hline & $S_{i}$ & ranking \\
\hline$A_{1}$ & 1.4479 & 1 \\
\cline { 2 - 3 }$A_{2}$ & 1.7515 & 3 \\
\cline { 2 - 3 }$A_{3}$ & 1.7240 & 2 \\
\cline { 2 - 3 }$A_{4}$ & 1.9107 & 11 \\
\cline { 2 - 3 }$A_{5}$ & 1.9279 & 14 \\
\cline { 2 - 3 }$A_{6}$ & 1.9199 & 13 \\
\cline { 2 - 3 }$A_{7}$ & 1.8733 & 7 \\
\cline { 2 - 3 }$A_{8}$ & 1.8732 & 6 \\
$A_{9}$ & 1.8251 & 5 \\
$A_{10}$ & 1.8899 & 12 \\
$A_{11}$ & 1.9162 & 9.5 \\
$A_{12}$ & 1.9081 & 9.5 \\
$A_{13}$ & 1.9081 & 4 \\
$A_{14}$ & 1.8185 & 15 \\
$A_{15}$ & 1.9544 & \\
\hline
\end{tabular}




\section{Conclusions}

Constructing project selection is an important issue, according to high risks and costs of mistakes. Therefore decision making based on multiple attributes eases it to prevent these likely problems. In construction evaluation problems, the decision maker selects some alternatives among different ones and it is necessary to consider different qualitative and quantitative criteria.

Evaluation of a set of alternatives regard to a set of quantitative or qualitative attributes is the main concentration of multi attribute decision making problems. In crisp MADM algorithms, subjective judgments and qualitative measures are translated into crisp numbers. This transformation means that decision maker ignores the uncertainty and ambiguity of his/her thinking and believes. Therefore some frameworks are presented to handle these uncertainties. According to uncertainty in the real world, we tried to calculate these parameters by uncertain data and in this paper, a new version of LINMAP method, originally presented in (Srinivasan, Shocker 1973), where decision maker's judges are expressed as grey number is proposed. The proposed method ranks alternatives by solving a linear programming that determines the attributes weight vector and an ideal solution. Then, the alternatives are ranked regard to their distances from PIS by specified weights. Application of the developed method is shown in two constructing examples that one of them was about ranking a set of various constructing projects for a developer company and another example was about ranking a set of constructing contractors. This suggests that the proposed method can be applied in different multi attribute decision making problems which contain uncertainty and ill-defined data and decision maker has not determined attributes weights priori.

\section{References}

Antucheviciene, J.; Zakarevicius, A.; Zavadskas, E. K. 2011. Measuring congruence of ranking results applying particular MCDM methods, Informatica 22(3): 319-33.

Aouam, T.; Chang, S. I.; Lee, E. S. 2003. Fuzzy MADM: an outranking method, European Journal of Operational Research 145(2): 317-328. http://dx.doi.org/10.1016/S0377-2217(02)00537-4

Balezentis, A.; Balezentis, T. 2011. A novel method for group multi-attribute decision making with two- tuple linguistic computing: supplier evaluation under uncertainty, Economic Computation and Economic Cybernetics Studies and Research 45(5): 5-29.

Bellman, R. E.; Zadeh, L. A. 1970. Decision making in a fuzzy environment, Management Science 17(4): 141-164. http://dx.doi.org/10.1287/mnsc.17.4.B141

Brauers, W. K. M.; Baležentis, A.; Baležentis, T. 2011. MULTIMOORA for the EU member states updated with fuzzy number theory, Technological and Economic Development of Economy 17(2): 259-290. http://dx.doi.org/10.3846/20294913.2011.580566

Chen, M. F.; Tzeng, G. H. 2004. Combining grey relation and TOPSIS concepts for selectingan expatriate host country, Mathematical and Computer Modelling 40(13): 1473-1490. http://dx.doi.org/10.1016/j.mcm.2005.01.006

Climaco, J. 1997. Multicriteria analysis. $1^{\text {st }}$ ed. Berlin: Springer-Verlag. http://dx.doi.org/10.1007/978-3-642-60667-0

Deng, J. L. 1982. Control problems of grey system, Systems and Control Letters 1(5): 288-294. http://dx.doi.org/10.1016/S0167-6911(82)80025-X 
Fouladgar, M. M.; Yazdani-Chamzini, A.; Zavadskas, E. K. 2011. An integrated model for prioritizing strategies of the Iranian mining sector, Technological and Economic Development of Economy 17(3): 459-483. http://dx.doi.org/10.3846/20294913.2011.603173

Hashemkhani Zolfani, S.; Rezaeiniya, N.; Zavadskas, E. K.; Turskis, Z. 2011. Forest roads locating based on AHP and COPRAS-G methods: an empirical study based on Iran, E\&M Ekonomie a Management 14(4): 6-21.

Hu, Y. C.; Hu, J. S.; Chen, R. S.; Tzeng, G. H. 2004. Assessing weights of product attributes from fuzzy knowledge in a dynamic environment, European Journal of Operational Research 154(1): 125-143. http://dx.doi.org/10.1016/S0377-2217(02)00652-5

Hwang, C. L.; Yoon, K. 1981. Multiple attribute decision making: methods and applications. New York: Springer-Verlag. http://dx.doi.org/10.1007/978-3-642-48318-9

Ishibuchi, H.; Tanaka, H. 1990. Multiobjective programming in optimization of the interval objective function, European Journal of Operation Research 48(2): 219-225.

http://dx.doi.org/10.1016/0377-2217(90)90375-L

Jahanshahloo, G. R.; Hosseinzadeh Lotfi, F.; Izadkhah, M. 2006. An algorithmic method to extend TOPSIS for decision-making problems with interval data, Applied Mathematics and Computation 175(2): 1375-1384. http://dx.doi.org/10.1016/j.amc.2005.08.048

Kersuliene, V.; Turskis, Z. 2011. Integrated fuzzy multiple criteria decision making model for architect selection, Technological and Economic Development of Economy 17(4): 645-666. http://dx.doi.org/10.3846/20294913.2011.635718

Kou, G.; Lu, Y.; Peng Y.; Shi, Y. 2012. Evaluation of classification algorithms using MCDM and rank correlation, International Journal of Information Technology \& Decision Making 11(1): 197-225. http://dx.doi.org/10.1142/S0219622012500095

Kuo, Y.; Yang, T.; Huang, G. W. 2008. The use of grey relational analysis in solving multiple attribute decision-making problems, Computers and Industrial Engineering 55(1): 80-93. http://dx.doi.org/10.1016/j.cie.2007.12.002

Le Teno, J. F.; Mareschal, B. 1998. An interval version of PROMETHEE for the comparison of building products' design with ill-defined data on environmental quality, European Journal of Operational Research 109(2): 522-529. http://dx.doi.org/10.1016/S0377-2217(98)00074-5

Li, D. F.; Yang, J. B. 2004. Fuzzy linear programming technique for multiattribute group decision making in fuzzy environments, Information Sciences 158(1): 263-275. http://dx.doi.org/10.1016/j.ins.2003.08.007

Li, D. F. 2008. Extension of the LINMAP for multiattribute decision making under Atanassov's intuitionistic fuzzy environment, Fuzzy Optimization and Decision Making 7(1): 17-34. http://dx.doi.org/10.1007/s10700-007-9022-x

Li, D. F.; Sun, T. 2007. Fuzzy LINMAP method for multiattribute group decision making with linguistic variables and incomplete information, International Journal of Uncertainty, Fuzziness and KnowledgeBased Systems (2): 153-173. http://dx.doi.org/10.1142/S0218488507004509

Lin, Y. H.; Lee, P. C.; Chang, T. P.; Ting, H. I. 2008. Multi-attribute group decision making model under the condition of uncertain information, Automation in Construction 17(6): 792-797. http://dx.doi.org/10.1016/j.autcon.2008.02.011

Moore, R. E. 1966. Interval Analysis. $1^{\text {st }}$ ed. London: Prentice Hall.

Özcan, T.; Çelebi, N.; Şakir, E. 2011. Comparative analysis of multi-criteria decision making methodologies and implementation of a warehouse location selection problem, Expert Systems with Applications 38(8): 9461-9471. http://dx.doi.org/10.1016/j.eswa.2011.02.022

Peng, Y.; Kou, G.; Wang, G.; Shi, Y. 2011. FAMCDM: a fusion approach of MCDM methods to rank multiclass classification algorithms, Omega 39(6): 677-689. http://dx.doi.org/10.1016/j.omega.2011.01.009 
Srinivasan, V.; Shocker, A. D. 1973. Linear programming techniques for multidimensional analysis of preference, Psychometrika 38(3): 337-369. http://dx.doi.org/10.1007/BF02291658

Stanujkic, D.; Magdalinovic, N.; Stojanovic, N.; Jovanovic, R. 2012. extension of ratio system part of MOORA method for solving decision-making problems with interval data, Informatica 23(1): 141-154.

Tsaur, R. C. 2011. Decision risk analysis for an interval TOPSIS method, Applied Mathematics and Computation 218(8): 4295-4304. http://dx.doi.org/10.1016/j.amc.2011.10.001

Turskis, Z.; Zavadskas, E. K. 2010. A novel method for multiple criteria analysis: grey additive ratio assessment (ARAS-G) method, Informatica 21(4): 597-610.

Vahdani, B.; Jabbari, A. H. K.; Roshanaei, V.; Zandieh, M. 2010. Extension of the ELECTRE method for decision-making problems with interval weights and data, International Journal of Advanced Manufacturing Technology 50(5-8): 793-800. http://dx.doi.org/10.1007/s00170-010-2537-2

Wang, R. C.; Chuu, S. J. 2004. Group decision-making using a fuzzy linguistic approach for evaluating the flexibility in a manufacturing system, European Journal of Operational Research 154(3): 563-572. http://dx.doi.org/10.1016/S0377-2217(02)00729-4

Xia, H. C.; Li, D. F.; Zhou, J. Y.; Wang, J. M. 2006. Fuzzy LINMAP method for multiattribute decision making under fuzzy environments, Journal of Computer and System Science 72(4): 741-759. http://dx.doi.org/10.1016/j.jcss.2005.11.001

$\mathrm{Xu}, \mathrm{Z} .2004$. A method based on linguistic aggregation operators for group decision making with linguistic preference relations, Information Sciences 166(1-4): 19-30. http://dx.doi.org/10.1016/j.ins.2003.10.006

Yazdani, M.; Alidoosti, A.; Zavadskas, E. K. 2011. Risk analysis of critical infrastructures using fuzzy COPRAS, Ekonomska Istrazivanja-Economic Research 24(4): 27-40.

Yue, Z. 2011. An extended TOPSIS for determining weights of decision makers with interval numbers, Knowledge-Based Systems 24(1): 146-153. http://dx.doi.org/10.1016/j.knosys.2010.07.014

Zadeh, L. A. 1965. Fuzzy sets, Information and Control 8(3): 338-353. http://dx.doi.org/10.1016/S0019-9958(65)90241-X

Zavadskas, E. K.; Vilutiene, T.; Turskis, Z.; Tamosaitiene, J. 2010a. Contractor selection for construction works by applying SAW-G and TOPSIS Grey techniques, Journal of Business Economics and Management 11(1): 34-55. http://dx.doi.org/10.3846/jbem.2010.03

Zavadskas, E. K.; Turskis, Z.; Tamosaitiene, J. 2010b. Risk assessment of construction projects, Journal of Civil Engineering and Management 16(1): 33-46. http://dx.doi.org/10.3846/jcem.2010.03

Zavadskas, E. K.; Turskis, Z.; Vilutienè, T. 2010c. Multiple criteria analysis of foundation instalment alternatives by applying Additive Ratio Assessment (ARAS) method, Archives of Civil and Mechanical Engineering 10(3): 123-141. http://dx.doi.org/10.1016/S1644-9665(12)60141-1

Zavadskas, E. K.; Turskis, Z. 2011. Multiple criteria decision making (MCDM) methods in economics: an overview, Technological and Economic Development of Economy 17(2): 397-427.

http://dx.doi.org/10.3846/20294913.2011.593291

Zimmerman, H. J. 1987. Fuzzy sets, decision making, and expert systems. $1^{\text {st }}$ ed., Boston: Kluwer Academic Publishers. http://dx.doi.org/10.1007/978-94-009-3249-4

Seyed Hossein RAZAVI HAJIAGHA received his BSc in Industrial Engineering at Islamic Azad University, 2005 and his M.A. in Industrial management at Allame Tabatabaei University, 2007. He has worked as a researcher at institute for Trade Studies and Researches since 2008. He has received his Ph.D at the same university, 2012. His research interest spans the fields of Operation research and Decision making methods under uncertainty. He has taught operation research at Allame University since 2009 and he has published some papers in these areas. 
Shide Sadat HASHEMI has received her BSc in Industrial management, at Damavand University, 2004 and her M.A. in Industrial management at Allame Tabatabaei University, 2008. She has worked as a researcher since 2009. Her research interests include operation management and Data envelopment analysis.

Edmundas Kazimieras ZAVADSKAS. Prof., Head of the Department of Construction Technology and Management at Vilnius Gediminas Technical University, Vilnius, Lithuania. He has a PhD in Building Structures (1973) and Dr Sc. (1987) in Building Technology and Management. He is a member of the Lithuanian and several foreign Academies of Sciences. He is Doctore Honoris Causa at Poznan, SaintPetersburg, and Kiev universities as well as a member of international organizations; he has been a member of steering and programme committees at many international conferences. E. K. Zavadskas is a member of editorial boards of several research journals. He is the author and co-author of more than 400 papers and a number of monographs in Lithuanian, English, German and Russian. Research interests are: building technology and management, decision-making theory, automation in design and decision support systems.

Hadi AKRAMI has received his BSc in Industrial Engineering, at Sharif University, 2003 and his M.Sc. in Industrial Engineering at Amirkabir University, 2007. He has worked as a researcher since 2005. His research interests include operation research and decision making. 